\title{
UPAYA PENINGKATAN KESELAMATAN PADA LOKASI RAWAN KECELAKAAN DI RUAS JALAN KOTA PEKANBARU
}

\author{
(Safety Improvement For Blackspot Area In Pekanbaru City) \\ Benny Hamdi Rhoma Putra ${ }^{1}$, Doni Rinaldi Basri ${ }^{1}$ \\ ${ }^{1}$ Program Studi Teknik Sipil Universitas Abdurrab \\ E-mail: benny@univrab.ac.id
}

\begin{abstract}
ABSTRAK
Kecelakaan lalu lintas bersifat stokastik dan terjadi akibat kombinasi dari beberapa faktor. Oleh karena besarnya kerugian akibat kecelakaan, maka diperlukan adanya suatu studi khusus dalam upaya peningkatan keselamatan lalu lintas di jalan raya. Pada penelitian ini mengambil kasus pada ruas jalan di Kota Pekanbaru. Data sekunder berupa laporan kecelakaan didapatkan dari Ditlantas Polda RIAU. Sedangkan data primer didapatkan lansung dari survey lokasi dan kuisioner dilokasi rawan kecelakaan tersebut. Tujuan dari penelitian ini adalah memilih lokasi rawan kecelakaan berdasarkan hasil pemeringkatan tingkat kecelakaan tertinggi, melakukan analisis permasalahan keselamatan, analisis konflik pada lokasi rawan kecelakaan, serta menghasilkan usulan penanganan untuk lokasi tersebut. Analisis pemeringkatan dilakukan menggunakan data kecelakaan selama 3 tahun dengan menggunakan kriteria frekuensi kecelakaan, EPDO. Dipilih tiga lokasi blackspot yaitu; Jl. Hangtuah KM 1-2, Jl. Hr.Subrantas KM 3-4, JI. Sukarno Hatta KM 1-2. Rekomendasi penanganan Jl. Hangtuah KM 1-2 adalah Pemasangan rambu pembatas kecepatan, Marka Menerus dan Pemasangan PJU. Pada lokasi Jl. HR.Subrantas KM 3-4 adalah Pemasangan Rambu Peringatan, Penambahan Zebra Cross, Perbaikan Perkerasan, Rambu larangan parkir di bahu jalan. padal lokasi III, Jl. Sukarno Hatta Km 1-2 rekomendasi penanganan adalah berupa pemasangan rambu pembatasan kecepatan dan memindahkan lokasi U-Turn yang dekat dengan persimpangan.
\end{abstract}

Kata Kunci: Ruas Jalan, Keselamatan lalu lintas, Blackspot, EPDO, Konflik lalu lintas

\begin{abstract}
Traffic accidents are stochastic and occur due to a combination of several factors. Due to disadvantages by accidents, it is necessary to have a study to improve road safety. This research take the case on the roads in Pekanbaru City. Secondary data in the form of accident report obtained from Ditlantas Polda RIAU. While the primary data obtained directly from the survey location and questionnaire location accident-prone. The purpose of this research is to find blackspot area based on the result of the highest accident rate ranking, perform safety analysis, conflict analysis at blackspot location, and recommend accident countermeasures for that locations. Rating analysis was conducted using accident data for 3 years using accident frequency criteria, EPDO. Blackspot area are; Jl. Hangtuah KM 1-2, Jl. Hr.Subrantas KM 3-4, Jl. Sukarno Hatta KM 1-2. Based on the safety problems, some safety remedial measures are proposed for these loaction. The safety remedial measures proposed for Jl. Hantuah KM 1-2 are Installation of speed limit sign, Road marking with continous line, and providing road lighting. The safety remedial measures proposed for Jl. HR. Subrantas are Installation of Warning Signs, Zebra Cross, Pavement Repair, Signs of parking ban on the shoulder of the road. The safety remedial measures proposed for JI Sukarno Hatta KM 1-2 are Installation of Speed Limit Sign, and relocation of u-turn.
\end{abstract}

Keywords: Road Segment, Traffic Safety, Blackspot, EPDO, Traffic Conflict 


\section{PENDAHULUAN}

Sepanjang 4 tahun terakhir 1220 kejadian kecelakaan berhasil dirangkum oleh Ditlantas Polda Riau. Pada tahun 2012 tercatat sebanyak 417 kejadian kecelakaan dan di tahun 2013 terjadi penurunan jumlah kecelakaan sebesar 262 kejadian. Selanjutnya ditahun 2014 terjadi kenaikan jumlah kejadian sebanyak 312 kecelakaan dan ditahun 2015 tercatat sebanyak 229 kejadian. Fenomena fluktuasi frekuensi kecelakaan dari 4 tahun ini menyebabkan sulitnya menentukan apakah penurunan dan kenaikan frekuensi kecelakaan pada lokasi studi disebabkan oleh perubahan kondisi lokasi tersebut, atau fluktuasi alami. Selain itu, Fenomena gunung es yang terjadi dikarenakan adanya kemungkinan tidak terekamnya data kecelakaan secara menyeluruh oleh kepolisian. Akibatnya total angka kecelakaan naik turun dan tidak dapat ditentukan dengan sangat pasti (Rhoma, 2015). Kecelakaan pada ruas jalan akan dapat menurunkan kinerja suatu ruas, tingkat keselamatan, kenyamanan dan kerugian moril serta materil. Untuk itu perlu dilakukan usaha meningkatkan keselamatan dan mereduksi masalah lalu lintas tersebut menuju jalan yang berkeselamatan.

Penelitian ini bertujuan untuk mengetahui tiga lokasi rawan kecelakaan pada ruas jalan di Kota Pekanbaru. Penelitian menggunakan data 3 tahun kejadian kecelakaan. Pemeringkatan lokasi rawan kecelakaan dilakukan dengan 2 kriteria. Selanjutnya analisis permasalahan keselamatan dilakukan dengan survey kondisi lokasi dan analisis konflik lalu lintas.

\section{METODE}

Metode yang dilakukan pada penelitian ini adalah melakukan pemeringkatan lokasi rawan kecelakaan di ruas Jalan Kota Pekanbaru. Pemeringkatan dilakukan sehingga didapatkan 3 lokasi rawan kecelakaan. Dari 3 lokasi kemudian dianalisis dengan 2 kriteria untuk tiap segmen jalan, sehingga didapatkan segmen jalan yang perlu ditangani.

\section{HASIL DAN PEMBAHASAN}

Data pada Tabel 1 berikut menampilkan data kecelakaan lalu lintas IRSMS dalam kurun waktu 3 tahun terakhir. Data tersebut dipilah berdasarkan lokasi terjadinya kecelakaan.

Tabel 1. Jumlah Kecelakaan Pada Ruas Jalan Di Pekanbaru

\begin{tabular}{cccc}
\hline No & Nama Ruas & $\begin{array}{c}\text { Jumlah } \\
\text { Kecelakaan }\end{array}$ & $\begin{array}{c}\text { Tipe } \\
\text { Jalan }\end{array}$ \\
\hline 1 & J. HANGTUAH & 38 & $22 U D$ \\
\hline 2 & J. HR. SOEBRANTAS & 35 & $42 D$ \\
\hline 3 & J. SOEKARNO HATTA & 34 & $42 D$ \\
\hline 4 & J. YOSSUDARSO & 26 & $42 \mathrm{D}$ \\
\hline 5 & J. JENDRAL SUDIRMAN & 23 & $62 \mathrm{D}$ \\
\hline 6 & J. SM AMIN & 19 & $62 \mathrm{D}$ \\
\hline
\end{tabular}

\section{PEMERINGKATAN RUAS JALAN RAWAN KECELAKAAN}

Pemeringkatan lokasi rawan kecelakaan dilakukan dengan 2 kriteria. Penentuan ruas jalan rawan kecelakaan ini dilakukan secara cluster dimana ke 3 jalan berada pada peringkat teratas pada Tabel 1 akan dibagi segemen-segmen jalan dengan rentang $1 \mathrm{~km}$ (HSM,2010). Adapun kriteria yang digunakan adalah 1) Frekuensi kecelakaan 2) Equivalent property damage only (EPDO).

\section{Frekuensi kecelakaan}

Metode ini merupakan metode paling sederhana. Metode ini membagi ke tiga jalan tersebut kedalam 1 $\mathrm{km}$. Pemeringkatan lokasi menggunakan Persamaan I beikut.

$$
F_{i}=\frac{A_{c i}}{L_{i} \times n}
$$

Dimana;

$\mathrm{Fi}=$ Frekuensi kecelakaan pada ruas ke-i (kecelakaan/Tahun/Km)

Aci = Jumlah kecelakaan yang di observasi pada ruas ke-i

$\mathrm{Li} \quad=$ Panjang segmen jalan ke-i $(\mathrm{km})$

$\mathrm{n} \quad=$ Jumlah periode data kecelakaan (tahun)

Berikut ini Tabel 2, Tabel 3 dan Tabel 4 menampilkan hasil perhitungan menggunakan kriteria ini untuk 3 ruas jalan.

Tabel 2. Kriteria Frekuensi pada Jl. Hangtuah

\begin{tabular}{ccccc}
\hline \multirow{2}{*}{$\begin{array}{c}\text { Nama } \\
\text { Jalan }\end{array}$} & $\begin{array}{c}\text { Segmen } \\
\text { Jalan }\end{array}$ & $\begin{array}{c}\text { Total } \\
\text { Laka/3 } \\
\text { tahun }\end{array}$ & $\begin{array}{c}\text { Frekuensi } \\
\text { (Fi) }\end{array}$ & Peringkat \\
\hline & $0-1$ & 0 & 0 & \\
\cline { 2 - 5 } & 2-Jan & 9 & 3 & 1 \\
\cline { 2 - 5 } $\begin{array}{c}\text { 3-Feb } \\
\text { Jl. }\end{array}$ & 1 & 0.33 & \\
\cline { 2 - 5 } Hangtuah & 4-Mar & 6 & 2 & \\
\cline { 2 - 5 } & 5-Apr & 3 & 1 & \\
\cline { 2 - 5 } & 6-May & 9 & 3 & 1 \\
& 7-Jun & 3 & 1 & \\
\hline
\end{tabular}

Kriteria frekuensi yang digunakan pada Tabel 2 diatas didapatkan lokasi rawan kecelakaan pada $\mathrm{J}$. Hangtuah, yaitu km 1-2 dan km 5-6.

Tabel 3. Kriteria Frekuensi pada JI. HR.Soebrantas

\begin{tabular}{lcccc}
\hline Nama Jalan & $\begin{array}{c}\text { Segmen } \\
\text { Jalan }\end{array}$ & $\begin{array}{c}\text { Total } \\
\text { Laka / } 3 \\
\text { tahun }\end{array}$ & $\begin{array}{c}\text { Frekuensi } \\
\text { (Fi) }\end{array}$ & Peringkat \\
& $0-1$ & 3 & 1 & 2 \\
\cline { 2 - 5 } & $1-2$ & 8 & 2.67 & 2 \\
$\begin{array}{c}\text { J. HR. } \\
\text { Soebrantas }\end{array}$ & $2-3$ & 8 & 2.67 & 1 \\
\cline { 2 - 5 } & $3-4$ & 9 & 3 & \\
& $4-5$ & 5 & 1.67 &
\end{tabular}


Dari tabel diatas didapatkan peringkat teratas pada Jl. HR. Soebrantas. Lokasi rawan kecelakaan berada pada $\mathrm{km} \mathrm{3-4}$

Tabel 4. Kriteria Frekuensi pada Jl.Sukarno Hatta

\begin{tabular}{ccccc}
$\begin{array}{c}\text { Nama } \\
\text { Jalan }\end{array}$ & $\begin{array}{c}\text { Segmen } \\
\text { Jalan }\end{array}$ & $\begin{array}{c}\text { Total } \\
\text { Laka / 3 } \\
\text { tahun }\end{array}$ & $\begin{array}{c}\text { Frekuensi } \\
\text { (Fi) }\end{array}$ & Peringkat \\
\hline $\begin{array}{c}\text { Jl. } \\
\text { Sukarno } \\
\text { Hatta }\end{array}$ & $0-1$ & 3 & 1 & \\
\cline { 2 - 5 } & $1-2$ & 7 & 2.33 & 1 \\
\cline { 2 - 5 } & $2-3$ & 4 & 1.33 & 2 \\
\hline $3-4$ & 1 & 0.33 & \\
\hline $4-5$ & 0 & 0 & \\
\hline $5-6$ & 3 & 1 & \\
\hline $6-7$ & 2 & 0.67 & \\
\hline $7-8$ & 3 & 1 & \\
\hline $11-12$ & 4 & 1.33 & \\
\hline $12-13$ & 1 & 0.33 &
\end{tabular}

Berdasarkan kriteria Frekuensi, pada ruas Jl. Sukarno Hatta diketahui lokasi blackspot berada pada km 1-2.

\section{Equivalent property damage only (EPDO)}

Kriteria ini menggunakan perbandingan biaya kecelakaan dari tingkat keparahan kecelakaan terhadap jenis kecelakaan tanpa korban (HSM,2010). Dari perbandingan tersebut didapat faktor pembebanan untuk tiap tingkat keparahan kecelakaan. Berikut hasil faktor pembebanan pada ditampilkan dalam Tabel 5.

Tabel 5. Hasil faktor pembebanan

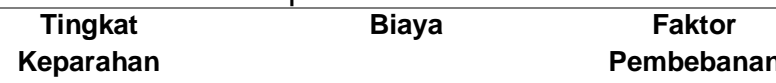

\begin{tabular}{lcc}
\hline Fatal & $\mathrm{Rp} 631,430,990.00$ & 15.79 \\
\hline Serious Injury & $\mathrm{Rp} 253,150,145.00$ & 6.33 \\
\hline Slight Injury & $\mathrm{Rp} 84,304,926.00$ & 2.11 \\
\hline PDO & $\mathrm{Rp40,000,000.00}$ & 1
\end{tabular}

Perhitungan dengan kriteria ini dilakukan dengan mengalikan faktor pembebanan diatas dengan tingkat keparahan tiap kejadian kecelakaan. Berikut ini Tabel 6 menyajikan nilai EPDO untuk Jalan Hangtuah, Tabel 7 menampilkan nilai Epdo dari Jalan HR. Subrantas dan Tabel 8 Jalan Soekarno Hatta.
Tabel 6. Kriteria EPDO pada Jalan Hangtuah

\begin{tabular}{|c|c|c|c|c|c|c|c|c|}
\hline \multirow[t]{2}{*}{ Ruas } & \multirow[t]{2}{*}{ Segmen } & \multirow{2}{*}{$\begin{array}{c}\text { Jumlah } \\
\text { Kecelaka } \\
\text { an }\end{array}$} & \multicolumn{4}{|c|}{$\begin{array}{c}\text { Jumlah Laka } \\
\text { 2014-2016 }\end{array}$} & \multirow{2}{*}{$\begin{array}{l}\text { Skor } \\
\text { EPDO }\end{array}$} & \multirow{2}{*}{$\begin{array}{c}\text { Peringka } \\
\mathrm{t}\end{array}$} \\
\hline & & & $\mathrm{Md}$ & $\mathrm{Lb}$ & $\mathrm{Lr}$ & $\mathrm{PDO}$ & & \\
\hline \multirow{8}{*}{$\begin{array}{c}\text { JL } \\
\text { HANGHT } \\
\text { UAH }\end{array}$} & KM 0-1 & 0 & 0 & 0 & 0 & 0 & 0 & \\
\hline & KM 1-2 & 9 & 2 & 4 & 3 & 0 & 63.23 & 1 \\
\hline & KM 2-3 & 1 & 0 & 0 & 1 & 0 & 2.11 & \\
\hline & KM 3-4 & 6 & 0 & 3 & 3 & 0 & 25.32 & \\
\hline & KM 4-5 & 3 & 1 & 0 & 2 & 0 & 20.01 & \\
\hline & KM 5-6 & 9 & 2 & 3 & 4 & 0 & 59.01 & 2 \\
\hline & KM 6-7 & 3 & 1 & 2 & 0 & 0 & 28.45 & \\
\hline & KM 7-8 & 3 & 1 & 0 & 2 & 0 & 20.01 & \\
\hline
\end{tabular}

Berdasarkan Tabel 6 diatas, didapatkan blackspot Jl. Hangtuah berada pada $\mathrm{Km} 1-\mathrm{Km} 2$ dengan nilai EPDO sebesar 63.23.

Tabel 7. Kriteria EPDO pada Jalan HR. Subrantas

\begin{tabular}{|c|c|c|c|c|c|c|c|c|}
\hline \multirow[t]{2}{*}{ Ruas } & \multirow{2}{*}{ Segmen } & \multirow{2}{*}{$\begin{array}{c}\text { Jumlah } \\
\text { Kecela } \\
\text { kaan }\end{array}$} & \multicolumn{4}{|c|}{$\begin{array}{c}\text { Jumlah Laka 2014- } \\
2016\end{array}$} & \multirow{2}{*}{$\begin{array}{l}\text { Skor } \\
\text { EPDO }\end{array}$} & \multirow{2}{*}{$\begin{array}{c}\text { Pering } \\
\text { kat }\end{array}$} \\
\hline & & & $\mathrm{MD}$ & LB & LR & PDO & & \\
\hline \multirow{5}{*}{$\begin{array}{c}\text { HR. } \\
\text { SOEBRA } \\
\text { NTAS }\end{array}$} & KM 0-1 & 3 & 0 & 0 & 2 & 1 & 4.22 & \\
\hline & KM 1-2 & 8 & 2 & 2 & 4 & 0 & 52.68 & \\
\hline & KM 2-3 & 8 & 2 & 0 & 5 & 1 & 42.13 & \\
\hline & KM 3-4 & 9 & 3 & 2 & 4 & 0 & 68.47 & 1 \\
\hline & KM 4-5 & 5 & 3 & 1 & 1 & 0 & 55.81 & 2 \\
\hline
\end{tabular}

Setelah dilakukan perhitungan menggunakan kriteria EPDO pada Jl. Subrantas, diketahui lokasi blackspot pada jalan ini berada pada $\mathrm{Km} 3$ hingga Km 4. Nilai Epdo untuk lokasi ini adalah 68.47.

Tabel 8. Kriteria EPDO pada Jalan Sukarno Hatta

\begin{tabular}{|c|c|c|c|c|c|c|c|c|}
\hline \multirow[t]{2}{*}{ JALAN } & \multirow[t]{2}{*}{ Segmen } & \multirow{2}{*}{$\begin{array}{c}\text { Jumlah } \\
\text { Kecela } \\
\text { kaan }\end{array}$} & \multicolumn{4}{|c|}{$\begin{array}{c}\text { Jumlah Laka 2014- } \\
2016\end{array}$} & \multirow{2}{*}{$\begin{array}{l}\text { Skor } \\
\text { EPDO }\end{array}$} & \multirow{2}{*}{$\begin{array}{c}\text { Pering } \\
\text { kat }\end{array}$} \\
\hline & & & MD & LB & LR & PDO & & \\
\hline \multirow{12}{*}{$\begin{array}{c}\text { JL. } \\
\text { SOEKAR } \\
\text { NO } \\
\text { HATTA }\end{array}$} & KM 0-1 & 3 & 2 & 0 & 1 & 0 & 33.69 & \\
\hline & KM 1-2 & 7 & 2 & 4 & 1 & 0 & 59.01 & 1 \\
\hline & KM 2-3 & 4 & 2 & 0 & 2 & 0 & 35.8 & \\
\hline & KM 3-4 & 1 & 1 & 0 & 0 & 0 & 15.79 & \\
\hline & KM 4-5 & 0 & 0 & 0 & 0 & 0 & 0 & \\
\hline & KM 5-6 & 3 & 1 & 1 & 1 & 0 & 24.23 & \\
\hline & KM 6-7 & 2 & 0 & 1 & 1 & 0 & 8.44 & \\
\hline & KM 7-8 & 3 & 0 & 1 & 2 & 0 & 10.55 & \\
\hline & KM 8-9 & 2 & 2 & 0 & 0 & 0 & 31.58 & \\
\hline & KM 9-10 & 0 & 0 & 0 & 0 & 0 & 0 & \\
\hline & KM 10-11 & 4 & 2 & 1 & 2 & 0 & 42.13 & 2 \\
\hline & KM 11-12 & 1 & 0 & 0 & 1 & 0 & 2.11 & \\
\hline
\end{tabular}

Nilai kriteria EPDO tertinggi di Jl. Sukarno Hatta berada pada lokasi $\mathrm{Km} \mathrm{1-} \mathrm{Km} 2$ sebesar 59.01. Selanjutnya $\mathrm{Km} \mathrm{10-11} \mathrm{berada} \mathrm{pada} \mathrm{peringkat} \mathrm{ke} \mathrm{dua}$ dengan nilai 42.13 .

Berdasarkan kedua kriteria yang sudah dihitung tersebut, berikut Tabel 9 menampilkan lokasi blackspot pada tiap ruas jalan yang diteliti 
Tabel 9. Lokasi Blackspot pada Tiap Jalan

\section{Ruas Jalan Lokasi \\ Blackspot}

\begin{tabular}{ll}
\hline JI. Hangtuah & Km 1-2 \\
\hline JI. HR. Subrantas & $\mathrm{Km} \mathrm{3-4}$ \\
\hline JI. Sukarno Hatta & $\mathrm{Km} \mathrm{1-2}$
\end{tabular}

\section{Permasalahan Keselamatan Lalu Lintas di J Hangtuah KM 1-2}

Jalan Hangtuah merupakan jalan dengan tipe 2/2 UD atau dua lajur dua arah tan pa median. Jalan ini juga dilewati oleh Transmetro Pekanbaru dan angkot Jurusan Pintu Angin.

Setelah didapatkan lokasi blackspot, selanjutnya dilakukan kajian terhadap data kecelakaan, survey konflik lalu lintas, dan survey permasalahan keselamatan. Dari survey konflik lalu lintas didapatkan konflik dominan yang terjadi pada lokasi blackspot. Sedangkan dari survey permasalahan keselamatan diketahui potensi bahaya (hazard) pada lokasi. Lokasi penelitian ini disajikan pada Gambar 2.

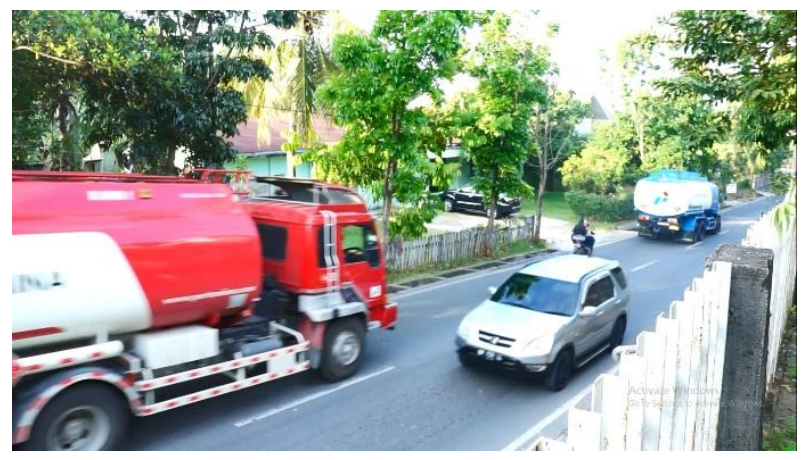

Gambar 2. Jl. Hangtuah Km 1-2

\section{Kajian Data Kecelakaan JI Hangtuah KM 1-2}

Data kecelakaan memuat informasi waktu, tingkat keparahan, kondisi pencahayaan dan tipe setiap kecelakaan. Hasil rangkuman 3 tahun kejadian kecelakaan dapat dilihat pada Lampiran 1

Berdasarkan rangkuman data kecelakaan tersebut, dapat dilakukan analisis deskripsi kecelakaan lalu lintas yang terjadi pada Jalan Hangtuah (Km 1 - 2) dengan pendekatan $5 \mathrm{~W}+1 \mathrm{H}$, yaitu

1. Where: Lokasi rawan kecelakaan yaitu pada segmen Jalan Hangtuah ( $\mathrm{Km} 1$ - 2) dengan panjang segmen $1 \mathrm{~km}$. Jalan ini merupakan jalan tipe 2/2 UD. Tata guna lahan didominasi oleh area komersil seperti ruko, warung, restoran, serta..

2. When: Waktu terjadinya kecelakaan didominasi pada waktu siang hari sebesar $89 \%$, dan pada waktu malam hari sebesar $11 \%$

3. What: Tipe kecelakaan yang dominan terjadi adalah tabrakan dari arah depan (tipe 52). Selanjutnya tipe tabrakan searah dari kendaraan belok kiri (tipe 73). Selanjutnya tabrakan belakang kendaraan depan belok kiri, tabrakan dengan objek diam dan tabrakan dari kendaraan yang datang dari kiri.

4. Why: Penyebab terjadinya kecelakaan didominasi oleh faktor manusia atau pengemudi. Namun faktor jalan turut memberikan andil terjadinya kecelakaan. Kondisi geometrik berupa turunan/tanjakan membuat pengemudi harus hati hati. Selanjutnya ada Bottle neck pada persimpangan dilokasi penelitian mengakibatkan tingginya angka konflik lalu lintas.

\section{Kajian Data Konflik Lalu Lintas JI Hangtuah KM 1-2}

Survey konflik lalu lintas dilakukan pada hari jumat tgl 2 Agustus 2017 pukul 16.00-17.00. konflik lalulintas dihitung berdasarkan potensi kejadian kecelakaan dilokasi. Berikut Tabel 9 dan Tabel 10 menampilkan hasil perhitungan konflik lalu lintas. Arah 1 adalah arah konflik pada arah turunan (meunuju timur) dan arah 2 adalah konflik yang terjadi pada kendaraan yang menuju arah barat yang menanjak.

Konflik dominan yang terjadi pada arah 1 adalah melambat searah sebesar $48 \%$. Konflik inien terjadi karena kendaraan didepan tiba tiba memperlambat kendaraan sehingga kdaraan lain harus mengambil tindakan memperlambat kendaraan juga untuk menghindari terjadinya kecelakaan. Kondisi geometrik berupa turunan membuat kendaraan bergerak lebih kencang. Selanjutnya konflik pindah lajur terjadi sebesar $24 \%$. Konflik ini terjadi akibat kendaraan berusaha untuk memotong kendaraan didepanya dengan masuk ke lajur lawan. Sebanyak 10\% konflik dengan pejalan kaki juga terjadi pada ruas jalan ini.

Tabel 10 Konflik Lalu Lintas pada Jl. Hangtuah KM 1-2 arah 1

\begin{tabular}{|c|c|c|c|c|c|}
\hline \multirow[b]{2}{*}{ Waktu } & \multicolumn{4}{|c|}{ Konflik arah 1 timur } & \multirow[b]{2}{*}{ Tota } \\
\hline & $\begin{array}{c}\text { Melambat } \\
\text { searah }\end{array}$ & $\begin{array}{l}\text { Pindah } \\
\text { Lajur }\end{array}$ & $\begin{array}{c}\text { Konflik } \\
\text { dengan } \\
\text { Pejalan } \\
\text { Kaki }\end{array}$ & $\begin{array}{c}\text { Putar } \\
\text { balik } \\
\text { Kanan }\end{array}$ & \\
\hline $\begin{array}{c}16.00- \\
16.15\end{array}$ & 8 & 6 & 3 & 2 & 19 \\
\hline $\begin{array}{l}16.15- \\
16.30\end{array}$ & 5 & 4 & 1 & 0 & 10 \\
\hline $\begin{array}{c}16.30- \\
16.45\end{array}$ & 5 & 3 & 1 & 0 & 9 \\
\hline $\begin{array}{l}16.45- \\
17.00\end{array}$ & 3 & 3 & 0 & 0 & 6 \\
\hline \multirow{2}{*}{ Jumlah } & 21 & 16 & 5 & 2 & 44 \\
\hline & $48 \%$ & $24 \%$ & $10 \%$ & $4 \%$ & \\
\hline
\end{tabular}


Tabel 11 Konflik Lalu Lintas pada Jl. Hangtuah KM 1-2 arah 2

\begin{tabular}{|c|c|c|c|c|c|}
\hline \multirow{2}{*}{ Waktu } & \multicolumn{4}{|c|}{ Konflik arah 2 Barat } & \multirow[t]{2}{*}{ Total } \\
\hline & $\begin{array}{c}\text { Melambat } \\
\text { searah }\end{array}$ & $\begin{array}{l}\text { Pindah } \\
\text { Lajur }\end{array}$ & $\begin{array}{c}\text { Konflik } \\
\text { dengan } \\
\text { Pejalan } \\
\text { Kaki }\end{array}$ & $\begin{array}{c}\text { Putar } \\
\text { balik } \\
\text { Kanan }\end{array}$ & \\
\hline $\begin{array}{l}16.15- \\
16.30\end{array}$ & 3 & 4 & 0 & 0 & 7 \\
\hline $\begin{array}{l}16.30- \\
16.45\end{array}$ & 3 & 2 & 0 & 1 & 6 \\
\hline $\begin{array}{l}16.45- \\
17.00\end{array}$ & 4 & 5 & 0 & 0 & 9 \\
\hline \multirow[t]{2}{*}{ Jumlah } & 10 & 11 & 0 & 1 & 22 \\
\hline & $45 \%$ & $32 \%$ & $0 \%$ & $4 \%$ & \\
\hline
\end{tabular}

Konflik dominan yang terjadi pada arah 2 adalah melambat searah sebesar $45 \%$. Konflik ini terjadi karena kendaraan didepan tiba tiba memperlambat kendaraan sehingga kendaraan lain harus mengambil tindakan memperlambat kendaraan juga untuk menghindari terjadinya kecelakaan. Selanjutnya konflik pindah lajur terjadi sebesar $32 \%$. Konflik ini terjadi akibat kendaraan berusaha untuk memotong kendaraan didepanya dengan masuk ke lajur lawan.

\section{Kajian Data Kuisioner JI Hangtuah KM 1-2}

Kuisioner disebarkan di lokasi penelitian sebanyak 15 sampel. Narasumber merupakan penduduk sekitar lokasi atau mereka yang sering berdada dilokasi penelitian ini. Quisioner disebarkan dilokasi untuk mengetahui permasalahan keselamatan lalu lintas pada lokasi yang tidak tercatat pada data kecelakaan. Hasil rekap kuisioner di tampilkan pada Lampiran 2. Dari kuisioner yaang disebar, dapat disimpulkan beberapa hal berikut ini;

a. Kejadian kecelakaan terjadi pada malam dan pagi hari

b. Kendaraan yang terlibat adalah sepeda motor, mobil dan angkot

c. Kondisi penerangan pada malam hari tidak ada dan hanya menggunakan penerangan dari kendaraan

d. Kecepatan pengendara cendrung tinggi

e. Perlu pemasangan rambu hati-hati, rambu pembatas kecepatan dan pemasangan paku jalan.

\section{Permasalahan Keselamatan Lalu Lintas di JI Hr. Subrantas KM 3-4}

Jalan Hr. Subrantas merupakan jalan dengan status jalan Provinsi. Tipe jalan ini adalah 4/2 D, yaitu 4 lajur 2 arah dengan median. Guna lahan disepanjang lokasi penelitian ini adalah berupa kawasan komersil dimana terdapat banyak ruko dan perkantoran.

\section{Kajian Data Kecelakaan HR. Subrantas KM 3-4}

Data kecelakaan yang berhasil dirangkum pada lokasi ini selama 3 tahun terakhir adalah sebanyak 9 kejadian. Rangkuman data Kecelakaan pada lokasi ini dapat dilihat pada Lampiran 1

Berdasarkan rangkuman data kecelakaan di Tabel V.11 diatas, maka dapat dilakukan analisis deskripsi kecelakaan lalu lintas yang terjadi pada Jalan HR Subrantas $(\mathrm{Km} \mathrm{3-4)}$ dengan pendekatan $5 \mathrm{~W}+1 \mathrm{H}$, yaitu

1. Where: Lokasi rawan kecelakaan yaitu pada segmen Jalan HR Subrantas (Km 3 - 4) dengan panjang segmen $1 \mathrm{~km}$. Jalan ini merupakan jalan tipe 4/2 D. Tata guna lahan didominasi oleh area komersil seperti ruko, warung, restoran, serta.

2. When: Dari semua data kecelakaan tercatat, waktu terjadinya kecelakaan pada waktu siang hari

3. What: Tipe kecelakaan yang dominan terjadi adalah tabrakan dengan objek diam (tipe 3). Selanjutnya tipe tabrakan antar kendaraan searah tanpa pergerakan berbelok dan ada juga kecelakaan tunggal .

4. Why: Penyebab terjadinya kecelakaan didominasi oleh faktor manusia atau pengemudi. Namun faktor jalan turut memberikan andil terjadinya kecelakaan.

Gambaran lokasi penelitian JI HR. Subrantas KM 3-4 ditampilkan pada gambar 2 berikut.

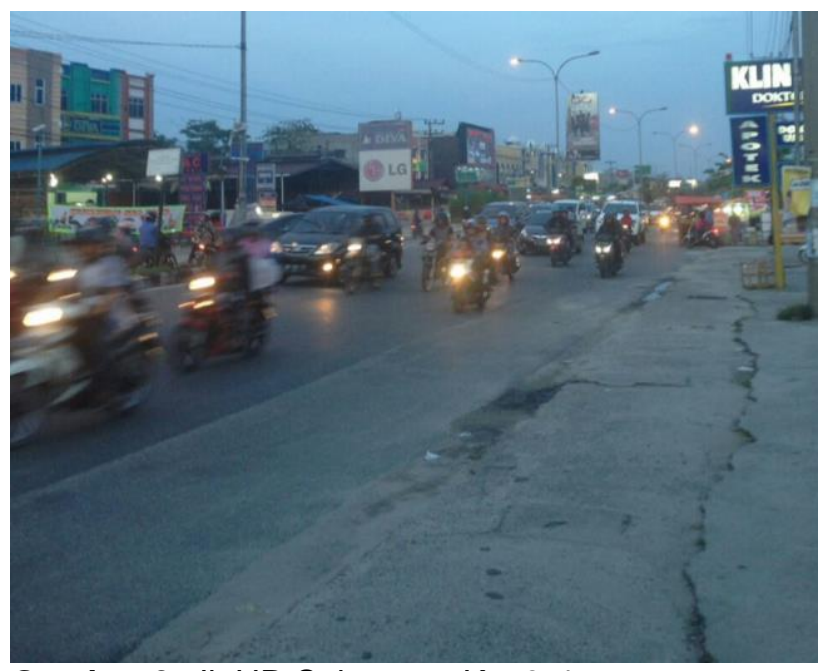

Gambar 2. JI. HR Subrantas Km 3-4

\section{Kajian Data Kuisioner JI HR. Subrantas KM 3-4}

Kuisioner disebarkan sebanyak 15 sampel kepada penduduk sekitar lokasi pengamatan. Berikut ini hasil analisis rekapitulasi kuisioner tersebut.

a. Mayoritas kecelakaan laulintas yang terjadi pada sore dan malam hari. Sore dan malam hari merupakan peak hour.

b. Kecelakaan umumnya melibatkan kendaraan ringan seperti mobil penumpang dan sepeda motor.

c. Kondisi penerangan pada malam hari terang dengan tersedianya Penerang Jalan Umum (PJU)

d. Permsalahan lalulintas yang berpotensi sebagai penyebab kecelakaan lalu lintas adalah terdapat 
kerusakan pada perkerasan. Kerusakan berupa terbentuk Alur atau rutting. Rutting merupakan deformasi permukaan perkerasan aspal kearah memanjang pada lintasan roda kendaraan. selainitu dibeberapa segmen bahu jalan juga mengalami crack dan berlubang

e. Permasalahan lainya adalah banyaknya Pedagang Kaki Lima (PKL) di sepanjang lokasi. PKL berjualan di bahu jalan sehingga dapat menurunkan kinerja ruas jalan dan mempertinggi probabilitas terjadinya kecelakaan

f. Konflik pengemudi dan pejalan kaki terpantau tinggi. Banyak aktivitas pejalan kaki yang menyeberang dan terlibat konflik dengan pengendara.

\section{Permasalahan Keselamatan Lalu Lintas di ال Sukarno Hatta KM 1-2}

Jalan Sukarno Hatta merupakan jalan kolektor sekunder dengan tipe jalan 4 lajur 2 arah dipisahkan median. Lebar jalan 7 meter tiap arah dengan tipe perkerasan lentur. Lebar bahu 1,5 meter diperkeras. Jalan ini dilewati oleh Angkot dan Bus TMP selain mobil penumpang dan sepeda motor.

\section{Kajian Data Kecelakaan JI JI Sukarno Hatta KM 1-2}

Berdasarkan rangkuman data kecelakaan di Tabel V.12 diatas, maka dapat dilakukan analisis deskripsi kecelakaan lalu lintas yang terjadi pada Jalan Sukarno Hata KM 1-2 dengan pendekatan $5 \mathrm{~W}+1 \mathrm{H}$, yaitu

1. Where: Lokasi rawan kecelakaan yaitu pada segmen Jalan HR. Sukarno Hata KM 1-2 dengan panjang segmen $1 \mathrm{~km}$. Jalan ini merupakan jalan tipe 4/2 D. Tata guna lahan didominasi oleh area komersil seperti ruko, warung, restoran, serta..

2. When: Dari semua data kecelakaan tercatat, waktu terjadinya kecelakaan pada malam hari sebesar $71 \%$ dan $29 \%$ terjadi pada siang hari

3. What: Tipe kecelakaan yang dominan terjadi adalah tabrakan depan - belakang (tipe 63), yaitu $28 \%$. Selanjutnya tipe tabrakan saat pindah lajur ke kanan, tabrakan depan - depan, tabrakan dengan kendaraan parkir di kiri jalan

4. Why: Penyebab terjadinya kecelakaan didominasi oleh faktor manusia atau pengemudi. Namun faktor jalan turut memberikan andil terjadinya kecelakaan.

Gambaran Lokasi Jl. Sukarno Hatta disajikan pada Gambar 3 berikut.

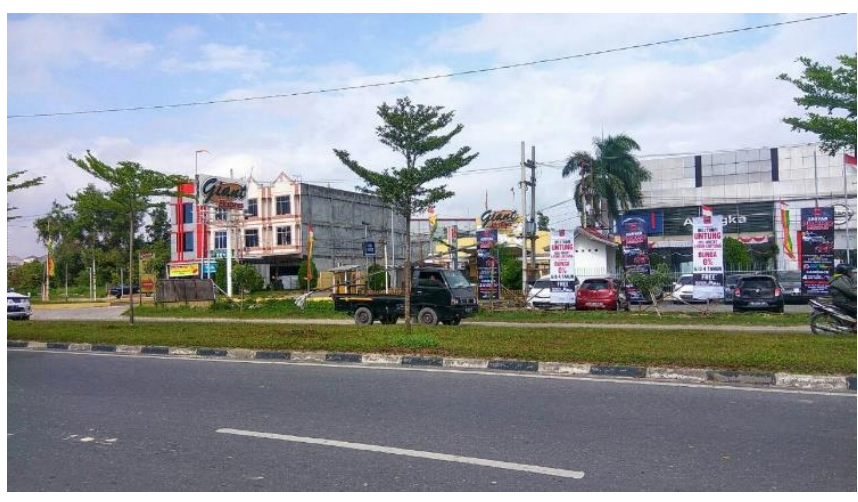

Gambar 3. Jl. Sukarno Hatta KM 1-2

\section{Kajian Data Kuisioner JI Sukarno Hatta KM 1-2}

Quisioner disebar sebanyak 10 sample dilokasi. Dari wawancara dengan kuisioner ini didapatkan permasalahan lalu lintas dilokasi yang berpotensi menyebabkan kecelakaan lalu lintas. Berikut hasil rekapitulasi wawancara dengan warga disekitar lokasi

a. Kejadian kecelakaan umumnya terjadi pada siang dan malam hari

b. Kendaraan yang terlibat adalah sepeda motor

c. Korban kecelakaan menderita luka berat

d. Frekuensi rerata kejadian kecelakaan sebesar 3 kejadian dalam 1 bulan

e. Permasalahan Ialu lintas yang kerap terjadi adalah kecepatan kendaraan yang tinggi pada lokasi penelitian. Kecepatan tinggi karena kondisi geomterik jalan dan perkerasan yang baik. Selain itu, ditemukan banyak pengendara yang melawan arus Ialulintas akibat jauhnya posisi U-turn

\section{Rekomendasi Penanganan Lokasi Rawan Kecelakaan}

Dari data dan analisis yang telah dilakukan, dapat di hasilkan penanganan lokasi rawan kecelakaan masing masing lokasi sebagai berikut;

\section{JI Hangtuah KM 1-2}

Kondisi lokasi penelitian ini memiliki kemiringan memanjang yang tidak landai yaitu sebesar $2,38 \%$. Hasil analisis konflik lalu lintas yang telah dilakukan pada lokasi ini, diketahui bahwa konflik lalu lintas dominan adalah melambat searah dan pindah lajur. Kondisi kendaraan yang terlibat dalam konflik melambat searah dikarekan tingginya kecepatan kendaraan sehingga ketika muncul halangan, maka pengendara seketika akan melakukan pengereman dan membahayakan pengendara lain. Selanjutnya, konflik pindah lajur terjadi ketika kendaraan kedua berusaha memotong kendaraan pertama dan terlibat konflik dengan kendaraan dari arah lawan. Berdasarkan data kuisioner, lokasi pada malam hari sangat gelap tanpa PJU. Rekomendasi penanganan pada lokasi ini adalah: 
a. Pemasangan rambu pembatas kecepatan

Pembatasan kecepatan dimaksudkan agar dapat mereduksi potensi terjadinya konflik melambat searah

b. Marka Menerus

Marka terputus yang saat ini ada diganti dengan marka menerus. Dengan penggantian ini dapat menekan pengguna jalan terlibat konflik pindah lajur.

c. Pemasangan PJU

Dengan kondisi jalan yang terang pada malam hari, pengendara akan medapatkan informasi yang cukup. Kondisi pencahayaan yang cukup dapat menekan terjadinya kecelakaan lalu lintas.

\section{JI HR. Subrantas KM 3-4}

Berdasarkan data kecelakaan yang diperoleh, tipe kecelakaan dominan terjadi pada lokasi ini adalah tabrakan dengan objek diam, kendaraan searah dan kecelakaan tunggal. Kecelekaan tipe ini terjadi karena tingginya kecepatan kendaraan dan kurang hati hatinya pengendara. Kondisi perkerasan di beberapa titik rusak, seperti retak, berlubang, bahkan terbentuknya Alur atau Rutting. Permasalahan lain berupa banyaknya PKL yang berjualan di bahu jalan dan banyak aktivitas pejalan kaki yang menyeberang. Rekomendasi penanganan pada lokasi ini adalah sebagai berikut;

a. Pemasangan Rambu Peringatan

Rambu peringatan dimaksudkan agar pengendara lebih berhati hati pada segmen jalan yang diteliti. Rambu diletakkan pada awal $\mathrm{Km} 3$ dan $\mathrm{Km} 4$. Dengan pemasangan rambu ini diharapkan agar menekan potensi kejadian kecelakaan dengan objek diam, dari belakang

b. Penambahan Zebra Cross

Pemberian fasilitas penyebrangan bagi pejalan kaki berupa Zebra Cross dapat menurunkan konflik dengan pejalan kaki. Pejalan kaki tidak akan sembarangan menyeberang dan lalu lintas akan lebih tertib

c. Perbaikan Perkerasan

Perbaikan perkerasan dapat dilakukan berupa patching dibeberapa titik. Perbaikan perkerasan bertujuan untuk meningkatkan kemantapan jalan dan menekan potensi terjainya kecelakaan.

d. Rambu larangan parkir di bahu jalan

Pemasangan rambu ini dapat mengurangi potensi terjadinya kecelakaan dengan objek diam. Konflik dengan objek diam dapat berupa kendaraan parkir atau Pedagang Kaki Lima. Dengan kecilnya aktivitas samping jalan dapat meningkatkan kinerja jalan dan menekan jumlah kejadian kecelakaan

\section{JI Sukarno Hatta KM 1-2}

Lokasi ini memiliki kondisi perkerasan dan geometrik jalan yang baik. Tipe kecelakaan yang sering terjadi akibat tingginya kecepatan kendaraan ketika melintasi segmen jalan ini adalah tabrak depan belakang. Dari hasil survei lokasi dan kuisioner, banyak ditemukan pengendara yang melawan arus untuk mempersingkat jarak tempuh. Berikut ini rekomendasi penanganan pada Ruas Jalan Sukarno Hatta KM 1-2

a. Rambu pembatasan kecepatan

Pemasangan rambu pembatasan kecepatan diharapkan dapat menurunkan angka kecelakaan pada lokasi ini. Kondisi permukaan jalan yang mantap dan lebarnya jalan membuat pengendara leluasa dan cendrung lengah

b. Memindahkan Posisi U-Turn pada lokasi

Penempatan lokasi U-turn didekat salah satu persimpangan di ruas jalan ini mengakibatkan besarnya jumlah pengendara yang melawan arus. Dengan menjauhkan lokasi Uturn dari persimpangan dapat menekan pelanggaran lalu lintas melawan arus.

\section{KESIMPULAN}

Adapun kesimpulan dari penelitian ini adalah;

1. Lokasi rawan kecelakaan di kota pekanbaru adalah JI. Hangtuah KM 1-2, JI. HR.Subrantas KM 3-4, dan JI. Sukarno Hatta KM 1-2.

2. Rekomendasi penanganan pada lokasi tersebut antara lain;

a. JI. Hangtuah KM 1-2

Pemasangan rambu pembatas kecepatan, Marka Menerus dan Pemasangan PJU.

b. JI. HR.Subrantas KM 3-4

Pemasangan Rambu Peringatan, Penambahan Zebra Cross, Perbaikan Perkerasan, Rambu larangan parkir di bahu jalan.

c. JI. Sukarno Hatta Km 1-2

Rekomendasi penanganan adalah berupa pemasangan rambu pembatasan kecepatan dan memindahkan lokasi U-Turn yang dekat dengan persimpangan.

\section{SARAN}

Perlu adanya kerjasama yang konkrit dan berkesinambungan antara instansi terkait seperti Kepolisian, Kementerian PUPR, Kementerian Perhubungan, Rumah Sakit, dan lain sebagainya, untuk merencanakan dan menyusun informasi database kecelakaan secara lengkap, akurat dan terperinci, dan juga peran aktif masyarakat dalam melaporkan setiap adanya kejadian kecelakaan yang terjadi disekitar mereka. Selain itu perlu dilakukan analisis mendalam lagi tentang lokasi u turn pada Jl. Sukarno Hatta KM 1-2

\section{REFERENSI}

AASHTO. (2010). Highway Safety Manual 1st Edition, Washington DC.

Departemen Permukiman dan Prasarana Wilayah. (2004). Pedoman Penanganan Lokasi Rawan Kecelakaan Lalu Lintas (Pd T-09-2004-B), Jakarta 
Rhoma, B.H. (2015). Upaya Peningkatan Keselamatan Pada Persimpangan Tak Bersinyal Di Kota Pekan Baru. Universitas Abdurrab.

Sofyan, Rachmat. (2016). Analisis Pemeringkatan Dan Penanganan Lokasi Rawan Kecelakaan Pada Ruas Jalan Nasional Di Kota Banda Aceh. Institut Teknologi Bandung. Bandung 